\title{
A bigger picture of how the Tibetan lakes change over the past decade revealed by CryoSat2 altimetry
}

\author{
Jiang, Liguang; Nielsen, Karina; Andersen, Ole B.; BauerGottwein, Peter
}

Published in:

Journal of Geophysical Research: Atmospheres

Link to article, DOI:

10.1029/2020JD033161

Publication date:

2020

Document Version

Publisher's PDF, also known as Version of record

Link back to DTU Orbit

Citation (APA):

Jiang, L., Nielsen, K., Andersen, O. B., \& BauerGottwein, P. (2020). A bigger picture of how the Tibetan lakes change over the past decade revealed by CryoSat2 altimetry. Journal of Geophysical Research: Atmospheres, 125(23), [e2020JD033161]. https://doi.org/10.1029/2020JD033161

\section{General rights}

Copyright and moral rights for the publications made accessible in the public portal are retained by the authors and/or other copyright owners and it is a condition of accessing publications that users recognise and abide by the legal requirements associated with these rights.

- Users may download and print one copy of any publication from the public portal for the purpose of private study or research.

- You may not further distribute the material or use it for any profit-making activity or commercial gain

- You may freely distribute the URL identifying the publication in the public portal 


\section{JGR Atmospheres}

\section{RESEARCH ARTICLE \\ 10.1029/2020JD033161 \\ A Bigger Picture of how the Tibetan Lakes Have Changed Over the Past Decade Revealed by CryoSat-2 Altimetry}

Key Points:

- More than 200 lakes have been monitored by CryoSat- 2 over the last decade (2010-2019)

- CryoSat-2 reveals three phases (rising-hiatus/decline-rising) of lake level change; hiatus/decline is widely observed during 2015/16 El Niño

- Mean change of lake level over the last decade is $2.19 \mathrm{~m}$, of which $56 \%$ occurs in the three most recent years

Correspondence to:

L. Jiang,

ljia@env.dtu.dk;

jianglg08@gmail.com

Citation:

Jiang, L., Nielsen, K., Andersen, O. B., \& Bauer-Gottwein, P. (2020). A bigger picture of how the Tibetan lakes have changed over the past decade revealed by CryoSat- 2 altimetry. Journal of Geophysical Research: Atmospheres, 125, e2020JD033161. https://doi.org/ 10.1029/2020JD033161

Received 24 MAY 2020

Accepted 7 NOV 2020

Accepted article online 13 NOV 2020

Author Contributions:

Formal analysis: Peter BauerGottwein

Funding acquisition: Peter BauerGottwein

Project administration: Peter BauerGottwein

Resources: Peter Bauer-Gottwein Writing - review \& editing: Karina Nielsen, Ole B. Andersen, Peter BauerGottwein

2020. American Geophysical Union. All Rights Reserved.

\author{
Liguang Jiang $^{1}$ iD, Karina Nielsen ${ }^{2}$ iD, Ole B. Andersen ${ }^{2}$ iD, and Peter Bauer-Gottwein ${ }^{1}$ iD \\ ${ }^{1}$ Department of Environmental Engineering, Technical University of Denmark, Kgs. Lyngby, Denmark, ${ }^{2}$ DTU Space, \\ National Space Institute, Technical University of Denmark, Kgs. Lyngby, Denmark
}

\begin{abstract}
Tibetan lakes are an effective indicator of climate change as they are highly sensitive to and directly affected by climate change. The past decade has seen the seven warmest years on record globally. Such observations have prompted questions about lake changes over the Tibetan Plateau. The dense coverage of the CryoSat-2 altimeter reveals large-scale patterns in this climate change signal. We investigate lake level variations of more than 200 lakes using altimetry observations from CryoSat-2 during the period 2010 to 2019. Combined with GRACE/GRACE-FO, we evaluate the water storage change of lakes and terrestrial water storage (TWS). We find that most studied lakes generally went through three phases of change, that is, rising-hiatus/decline-rising, albeit lakes in the north Tibetan Plateau, show higher rising rates. Results also show that lake levels are widely affected by the 2015/16 El Niño event across the entire Inner Plateau via reduced precipitation. Above normal precipitation during 2016-2018, resulted in a sharp rise of $\sim 1.22 \mathrm{~m}$ on average, accounting for $56 \%$ of the decadal lake level rise (mean/median: 2.19/1.85 m). TWS in the Inner Tibetan Plateau accumulated a net gain of $70.5 \mathrm{~km}^{3}$, which is dominated by the net gain of lake water storage $\left(\mathrm{ca} .63 .3 \mathrm{~km}^{3}\right)$. The interannual TWS variation is found to be associated mainly with precipitation. In particular, extreme conditions such as the 2015/16 El Niño, had a profound negative impact on the TWS. The findings in this study shed new light on the response of Tibetan lakes to recent decadal environmental changes.
\end{abstract}

\section{Introduction}

The Tibetan Plateau (TP) is well known as the "Water Tower of Asia" given that 10 major rivers originate from its high mountains (Figure 1) and that it influences more than 1.4 billion people in the downstream areas (Immerzeel et al., 2010). With an average elevation of more than 4,000 $\mathrm{m}$ and an annual average temperature of around $0^{\circ} \mathrm{C}$, the $\mathrm{TP}$ has huge areas of glaciers and permafrost (T. Yao et al., 2018). Moreover, the TP is home to over 1,000 lakes, which are of great importance for the local eco-environment and water supply for wild animals. The TP has experienced significant warming (twice the global average) and extreme climate events during the past 50 years (Chen et al., 2015). One of the consequences of climate change is the intensification of the water cycle (Durack et al., 2012), which in turn affects regional water availability by transport and redistribution of water via atmospheric circulations and hydrological processes. This change is directly reflected in lake changes over the inner TP during the past decades (G. Zhang et al., 2020). On the other hand, due to rare human intervention, these lakes respond naturally to large-scale climate variability and regional hydrological processes; thus, the Tibetan lakes can be seen as a valid indicator of environmental change (Sheng \& Yao, 2009; G. Zhang et al., 2016).

In addition to their value as water resources, lakes are important landscape units playing a crucial role in water cycle and land surface energy cycle and thus affect regional climate (Notaro et al., 2013; Scott \& Huff, 1996). For instance, lakes can change turbulent fluxes as well as surface downward shortwave radiation flux due to changes in local atmospheric moisture and convective cloud cover; moreover, lakes strongly modulate evaporation and precipitation as well as snowmelt (Lazhu et al., 2016; Notaro et al., 2013; Wu et al., 2019). In turn, large-scale fluctuation of climate (such as NAO and ENSO) and regional climate (e.g., glacier melting, permafrost degradation, and enhanced hydrological cycle) alter the phenology and lake water budgets (Lei et al., 2019; Liu et al., 2018; Zhang, Tang, et al., 2017). Widely distributed lakes over the TP may respond differently to climate change across the diverse climate conditions and geographic regions (Figure 1). Understanding how the water and energy budgets respond to climate change and whether lakes behave homogeneously requires extensive observations. However, the TP remains 


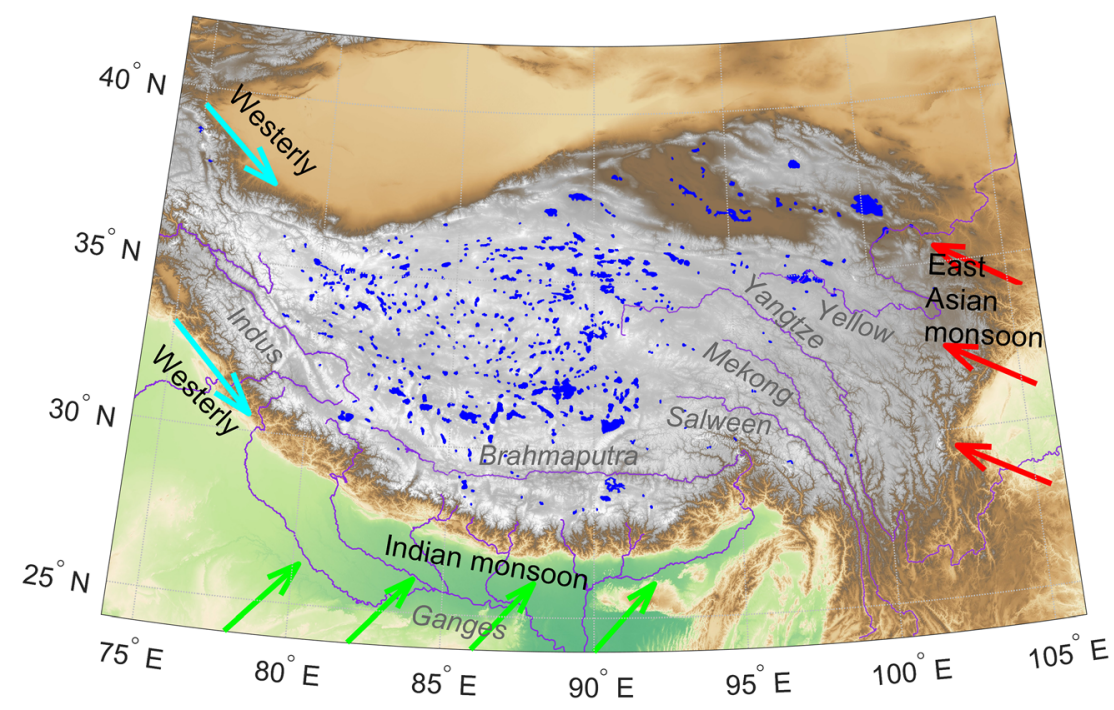

Figure 1. Distribution of lakes over the Tibetan Plateau, accompanied with colored topography, major rivers, and three large-scale atmospheric circulations, that is, the westerly jet, Indian monsoon, and East Asian monsoon.

largely ungauged, and only a small fraction of those lakes is monitored with in-situ instrumentation (Lei et al., 2019). Data collection in such a harsh and remote environment is difficult and expensive, and we are in dire need of alternative ways of monitoring lake changes over the TP (Li, Long, et al., 2019; G. Zhang et al., 2020).

Thanks to the availability of satellite observations, we are able to take a closer look at lake changes on a large scale. For instance, NASA's Landsat program has undoubtedly transformed our ability to understand the spatial coherence/variability of lake shrinking and expansion during the past 40 years (G. Zhang et al., 2020). Zhang et al. (2019) compiled lake surface extents over the TP from Landsat MSS/TMETM+/OLI imagery acquired between 1970 and 2018. There is a slight decline (-5.6\%) of the total lake area from 1970 to 1995; then a pronounced increase of 23\% from 2000 to 2018 is revealed. To understand the water budget and quantify the contributions of different driving factors for lake changes, lake surface extent alone is insufficient (F. Yao et al., 2018; Zhang, Yao, et al., 2017). Combining surface water extent with global digital elevation models (DEMs), some studies estimated lake storage variations by establishing the relationship between lake area and lake level (Qiao et al., 2019; F. Yao et al., 2018). However, the uncertainty of global DEMs is usually above a few meters (Rodríguez et al., 2006), which may affect the estimation of lakes with small level change. Ocean-oriented altimetry has gradually been extended to cryospheric and hydrologic studies (Fetterer et al., 1992; Koblinsky et al., 1993). Altimetry observations add information about lake changes in the vertical dimension, and combined with lake extent, volumetric water changes can be calculated (J.-F. Crétaux et al., 2016). The first studies to quantify volumetric lake changes over the TP mainly used ICESat altimetry data (2003-2009) (Song et al., 2013; G. Zhang et al., 2013). Increased availability of altimetry data sets has allowed researchers to better quantify water volume change (J. F. Crétaux \& Birkett, 2006; J. Wang et al., 2018; F. Yao et al., 2018). Combined with GRACE-derived total water storage, the dynamics of surface water storage and ground water storage can be assessed (Jiang et al., 2017a; G. Zhang et al., 2013). Nevertheless, previous studies mainly investigated level/storage variation of a limited number of lakes due to the lack of lake level data sets (see a review by G. Zhang et al., 2020). Among past and present satellite altimetry missions, CryoSat-2 stands out due to its high coverage and long-time records (since 2010) among other distinctive features (Jiang, Schneider, et al., 2017; Wingham et al., 2006). This is a very important feature for the monitoring of the widely distributed Tibetan lakes (Figure 1).

CryoSat-2 was launched in April 2010 into a non-sun-synchronous orbit with a 369-day repeat period. This orbit also has a 30-day subcycle, which results in dense ground tracks, that is, an intertrack spacing of $7.5 \mathrm{~km}$ at the Equator over one full repeat cycle (Wingham et al., 2006). This special geodetic orbit enables many opportunities to study inland water bodies. For example, many more lakes are sampled compared to missions with a short-repeat cycle (Jiang et al., 2017a; Jiang, Schneider, et al., 2017); longitudinal elevation 
profiles of rivers can be retrieved (Bercher et al., 2013; Jiang et al., 2017a); parameterization of river models and hydrodynamic simulations can also be improved by using distributed CryoSat-2 observations (Jiang, Madsen, et al., 2019; Schneider et al., 2017, 2018). The drawback is that it is difficult to construct water level time series at certain virtual stations (Jiang, Schneider, et al., 2017).

CryoSat-2 is equipped with a novel Synthetic Aperture Radar/Interferometric Radar Altimeter (SIRAL) instrument (Garcia et al., 2014; Wingham et al., 2006). It can operate in three modes, that is, low resolution mode (LRM), SAR mode, and SARIn mode over different regions. When SAR/SARIn mode is enabled, the instrument operates in bursts, that is, sending a burst of pulses with a frequency of $\sim 18,000 \mathrm{kHz}$ (Wingham et al., 2006). The returning echoes are processed coherently (Doppler beam formation) in the along-track direction (Keith Raney, 1998; Wingham et al., 2006). In this way, a smaller footprint is achieved, that is, ca. 300-400 $\mathrm{m}$ in the along-track direction and ca. 1.65 to a few $\mathrm{kms}$ in the cross-track direction depending on the flatness of the illuminated area (Garcia et al., 2014; Jiang, Schneider, et al., 2017). Besides, the tracking range window and measurement range window of CryoSat-2 SARIn mode are 480 and $240 \mathrm{~m}$, respectively, which raises the possibility to fully capture the echoes from water over rugged topography (Wingham et al., 2006).

This study focuses on the variations of the Tibetan lakes to understand how the Tibetan lakes have responded to global warming? Did lakes behave homogeneously, especially during the 2015/16 El Niño? If not, was there any distinct spatial pattern? We aim to present a bigger picture of variations of the Tibetan lakes over the last decade using consistent altimetry data from CryoSat-2. Finally, this study examines the lake storage variations and total water storage over the TP using GRACE/GRACE-FO data sets. This study for the first time shows the water level as well as storage variations of more than 200 lakes. And the findings are expected to contribute to a better understanding of lake changes over the latest decade.

\section{Materials and Methods}

\subsection{CryoSat-2 Data Set}

CryoSat-2 has been delivering altimetry data since its launch in April 2010. Over the TP, CryoSat-2 operates in SARIn mode, which enhances the along-track spatial resolution to $300 \mathrm{~m}$ (Jiang, Schneider, et al., 2017; Wingham et al., 2006). In this study, baseline $\mathrm{C}$ data are used as input; level $1 \mathrm{~b}$ and level 2 processing are facilitated by the ESA GPOD platform (Dinardo et al., 2014). Water surface elevation is derived using the SAMOSA+ retracker (Dinardo et al., 2018). The data set is archived at the ftp site ftp://eogrid.esrin.esa. int/0039 and can be accessed after registration.

\subsection{Auxiliary Data}

\subsubsection{GRACE and GRACE-FO}

The Gravity Recovery And Climate Experiment (GRACE) and GRACE Follow-On (GRACE-FO) provide valuable data that allow us to accurately detect terrestrial water storage (TWS) change (Tapley et al., 2019). In this study, we use JPL GRACE and GRACE-FO level 3 mascon (Version2/RL06) equivalent water height product (https://podaac.jpl.nasa.gov/GRACE). This solution uses a priori constraints to estimate global monthly gravity fields in terms of mass concentration functions to minimize the effect of measurement errors. This results in a better signal-to-noise ratio of the mascon fields compared to the conventional spherical-harmonic solutions (Watkins et al., 2015). Time invariant scaling factors are applied as recommended. The native resolution of a single mascon is $3^{\circ} \times 3^{\circ}(\sim 300 \times 300 \mathrm{~km})$. However, the data set is provided at a resolution of $0.5^{\circ} \times 0.5^{\circ}$ (https://grace.jpl.nasa.gov/data/get-data/ jpl_global_mascons/).

\subsubsection{Meteorological Data}

The Global Precipitation Climatology Project (GPCP version 2.3) monthly precipitation data set from 1979 to present combines observations and satellite precipitation data into $2.5^{\circ} \times 2.5^{\circ}(\sim 250 \times 250 \mathrm{~km})$ global grids (Adler et al., 2018). The Global Precipitation Measurement (GPM) Integrated Multi-satellite Retrievals (IMERG) is also used due to its finer spatial resolution of $\sim 10 \times 10 \mathrm{~km}$ (Huffman et al., 2017). Multivariate ENSO Index (MEI) climate index is downloaded from NOAA Earth System Research Laboratory (https://www.esrl.noaa.gov/psd/gcos_wgsp/Timeseries/). 


\subsubsection{Soil Moisture}

Soil moisture data are from the ESA Climate Change Initiative soil moisture product. In this study, we use the monthly combined (a blend of passive and active products) product. The spatial resolution is $0.25^{\circ} \times 0.25^{\circ}$ or roughly $\sim 25 \times 25 \mathrm{~km}$. Data of nearly 10 years (2010-2019 September) are used.

\subsubsection{Actual Evapotranspiration}

Monthly actual evapotranspiration data are from the Global Land Evaporation Amsterdam Model (GLEAM). The Priestley-Taylor equation is used in GLEAM to calculate potential evapotranspiration based on observations of surface net radiation and near-surface air temperature. Actual evapotranspiration is calculated using a multiplicative evaporative stress factor based on satellite observations of microwave vegetation optical depth, root-zone soil moisture, and so forth. For more details, please refer to Martens et al. (2017). In this study, we use the latest v3.3b monthly data sets with a spatial resolution of $\sim 25 \times 25 \mathrm{~km}$. This data set spans nearly 16-year period 2003-2018 (September). Aligning with CryoSat-2, only data after 2010 are used.

\subsection{Altimetry Data Processing}

To analyze lake level variations, altimetry data have to be further processed to construct time series. Detailed procedures are as follows.

1. Altimetry measurements over lakes are extracted based on the global surface water occurrence data set (Pekel et al., 2016). Given that there are enough measurements (tens to hundreds) per track for lakes, an $80 \%$ occurrence threshold is used to select measurements over lakes.

2. Given that CryoSat-2 operates in closed-loop mode (the altimeter continuously adjusts the range window based on previous measurements), signals can be just noise even when the satellite is over a lake. Therefore, we first compare the position of the range window against the lake elevation from a DEM (Altimeter Corrected Elevations, ACE2) to discard invalid measurements (Jiang et al., 2020). To detect spurious measurements, pulse peakiness (the ratio of maximum echo to the sum of echoes in a waveform) is used. Lakes are generally very reflective and therefore result in a high value of pulse peakiness. A threshold of 0.01 is used based on investigation over a representative subset of lakes.

3. To further remove outliers in each track, we exclude those further than 2 deviations away from the median value. Here, the deviation is estimated using the median of absolute deviation (MAD) method. A detailed description can be found in Jiang, Andersen, et al. (2019).

4. Time series for each lake are calculated using the "tsHydro" tool available from Github (https://github. com/cavios/tshydro). This tool efficiently estimates along-track water level in the presence of outlying measurements. For more information, please refer to Nielsen et al. (2015).

5. A linear trend is estimated based on robust least squares regression. This method uses an iteratively reweighted least squares algorithm which gives lower weight to points that do not fit well. The results are less sensitive to outliers in the data (Holland \& Welsch, 1977).

6. Annual mean lake level is calculated by averaging all observations within a year. Annual lake levels are used to estimate interannual lake storage variation.

\subsection{Cluster Analysis}

A spatial autocorrelation describes the tendency for geographically close areas or sites to have similar behavior. Moran's I (Moran, 1950) is an index that is commonly used as a first measure of spatial autocorrelation. It detects deviations from spatial randomness and determines whether neighboring samples are more similar than what is expected under the null hypothesis. This spatial statistical index is used here to provide insight into the spatial patterns of lake variations. The first step is the construction of a spatial weights matrix, which considers and expresses the strength of correlation between pairs of lake level change rates in various locations. The definition of weight is based on the Euclidean distance. A distance threshold of 5.26 degrees is derived based on an empirical semivariogram, which describes the relationship between correlation and distance. In the second step, we calculate Moran's I (Anselin, 1995). Local Moran's I indicates if lakes with similar change rates are in clusters or are randomly distributed. It provides results in five categories: high-high cluster, low-low cluster, high-low outliers, low-high outliers, and not significant. High-high cluster refers to lakes that have high change rates and are surrounded by lakes with high change rates. Likewise, low-low indicates lakes that have low change rates and are surrounded by lakes with low 

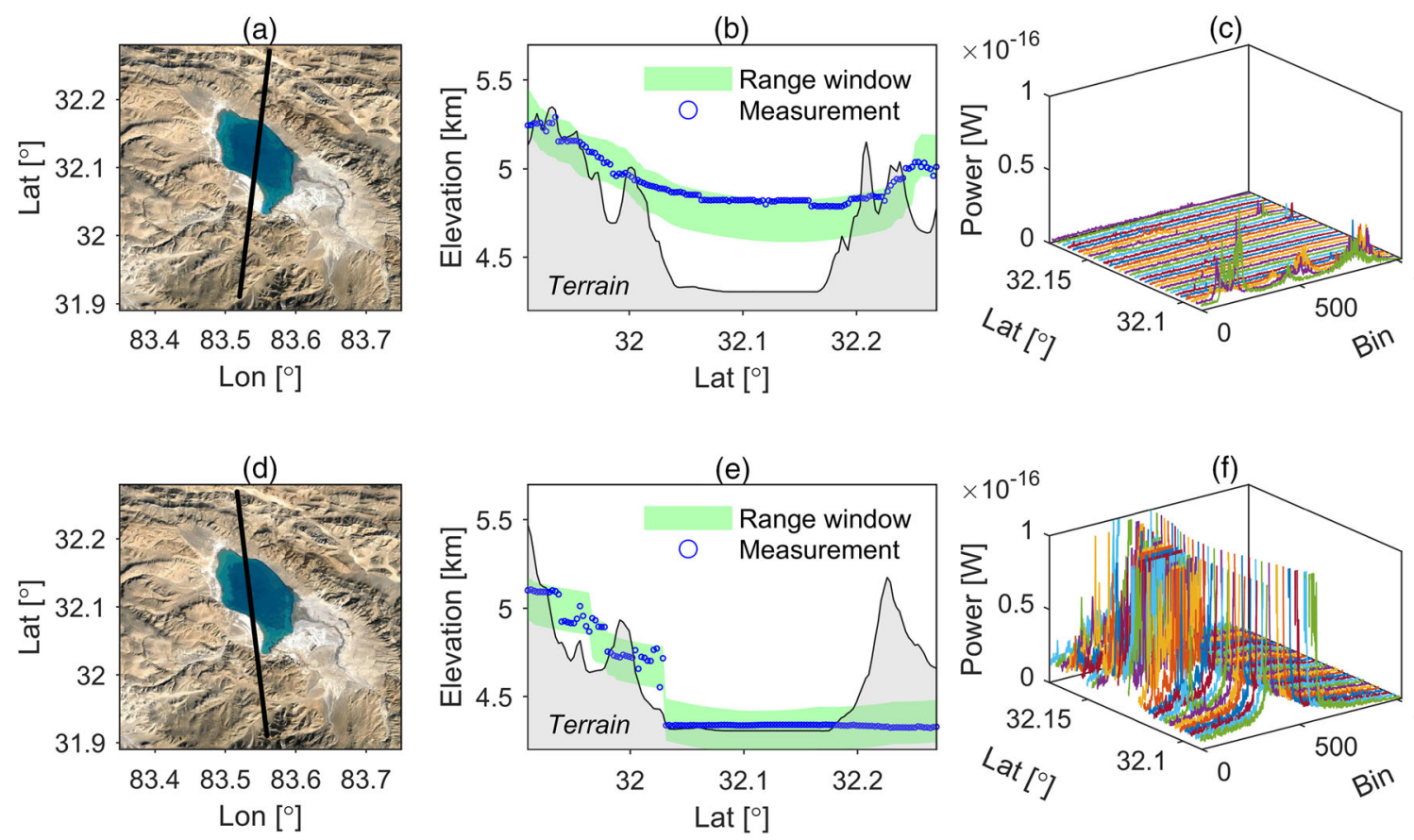

Figure 2. Exemplary range window position in closed-loop over the Cam Co $\left(104 \mathrm{~km}^{2}\right)$ surrounded by rugged terrain. (a) and (d) Locations of a descending/an ascending ground track (dates: 30 July 2018; 1 June 2018); (b) and (e) illustration of underlying terrain along the ground track, adaptation of range window, and altimetry-derived heights; (c) and (f) waveforms of measurements over the lake.

change rates. These two categories show a significantly positive correlation, while the outliers indicate a negative correlation between lakes and their neighbors.

\subsection{Water Storage Change Estimation}

To calculate lake volumetric changes, ideally the lake area of the corresponding year should be used. Here a constant lake area (year 2014) is used since the change in lake area is relatively small for most lakes. The lake extent is derived from Global Surface Water Explorer as used in our previous study (Jiang et al., 2017a). As argued by Kleinherenbrink et al. (2015) the maximum increase of lake area per meter lake level change is approximately $5 \%$. Therefore, a cylindric shape assumption is used to estimate yearly water storage change. Our previous study indicates that the error introduced by this approximation is $2.5 \%$ over 70 lakes (Jiang et al., 2017a).

\section{Results and Analyses}

\subsection{CryoSat-2 Data Analysis}

Based on the lake database we used (575), CryoSat-2 crosses 558 lakes in total. However, due to the difficulties intrinsic to positioning the range window, some measurements are invalid. Figure 2 shows an example over a medium sized lake, Cam Co. For the descending pass, CryoSat-2 failed to adjust the range window to the elevation of the lake surface; thus, none of the waveforms contain a signal from the lake (Figure 2c). Therefore, all measurements are discarded in this case. On the contrary, the ascending pass shows valid measurements. We can see that the range window had been adjusted to the lake surface elevation (Figure 2e). Correspondingly, the recorded waveforms show clear peaks indicating signals reflected by lake water (Figure 2f). This example demonstrates the problems that CryoSat-2 has over rugged topography. This occurs over relatively small lakes that mostly are surrounded by mountains. By comparing the range window against a DEM, we discarded all invalid measurements. After data editing, we focus the analysis on 262 lakes with an area larger than $10 \mathrm{~km}^{2}$ and with a minimum of 10 overpasses (to ensure sufficiently long time series). 
Table 1

Group Statistics of Lake Level Change Rates by Their Magnitudes

\begin{tabular}{lcccc}
\hline Group & Num. $(\%)$ of lakes & Median rate $(\mathrm{m} / \mathrm{yr})$ & Num. $(\%)$ of lakes $(p<0.05)$ & Median rate $(\mathrm{m} / \mathrm{yr})(p<0.05)$ \\
\hline$<-0.2$ & $8(3)$ & -0.26 & $8(3)$ & -0.26 \\
{$[-0.2,0]$} & $54(21)$ & -0.05 & $26(10)$ & -0.11 \\
{$[0,0.15]$} & $89(34)$ & 0.07 & $43(16)$ & 0.11 \\
{$[0.15,0.3]$} & $41(16)$ & 0.23 & $40(15)$ & 0.23 \\
{$[0.3,0.5]$} & $43(16)$ & 0.37 & $43(16)$ & 0.37 \\
$>0.5$ & $27(10)$ & 0.69 & $27(10)$ & 0.69 \\
$>0$ & $200(76)$ & 0.20 & $153(58)$ & 0.27 \\
$<0$ & $62(24)$ & -0.06 & $34(13)$ & -0.12 \\
All & $262(100)$ & 0.12 & $187(71)$ & 0.22 \\
\hline
\end{tabular}

\subsection{Trend of Lake Levels}

The results (Table 1) of the trend analysis show that an overall positive trend at a median rate of $0.12 \mathrm{~m} / \mathrm{yr}$ is found for 262 lakes. A large proportion of the lakes (76\%) were experiencing a positive trend, of which 56\% had a high increasing rate beyond $0.15 \mathrm{~m} / \mathrm{yr}$ and were statistically significant $(p<0.05)$. On the contrary, only 34 (13\%) show a significant negative trend and their linear rates are relatively small. Overall, 187 lakes are showing significant changes at the level of 0.05 .

Figure 3 shows the distribution of decadal linear rates of lake level change. Clearly, the decadal linear rate distribution is uneven and dominated by rising trends. The histogram of rates is apparently skewed. In addition, rates increase with higher latitude, especially lakes located in the Inner TP (Figure 3c). We also ranked the rates by lake area (not shown). But no obvious relationship can be identified, which indicates that rates are independent of lake area.

Figure 4 shows the spatial distribution of trends of lake level change. Changes in lake levels display a remarkable contrast between the north and south of the Inner TP. Specifically, lakes located in the north of the Inner TP generally have higher rates, while those in the south show smaller or negative rates. Note that there is one exception in the north showing a declining rate $(<-0.2 \mathrm{~m} / \mathrm{yr})$ due to an abrupt drop in 2018 although it was continuously rising before 2018. It is noteworthy that all lakes with a sharp rising trend $\left(>0.5 \mathrm{~m} / \mathrm{yr}\right.$ ) are located beyond $33^{\circ} \mathrm{N}$. Lakes in the Qaidam Basin show low regional consistency. Those located in the Yellow river source region are generally declining but mostly at rates that are not statistically significant.

Spatial analyses revealed the presence of autocorrelation in the distribution of lake change rates. The map of clusters and outliers categorized based on local Moran's $I$ is shown in Figure 5. Clearly, lake level change rates are not randomly distributed across the TP. Instead, there are strong relationships between lakes. The main types of clusters are high-high and low-low groups. The hotspots of high rates (high-high clusters) are concentrated in the north of Inner TP, while low-low clusters are mainly located in the south of Inner TP as well as the Brahmaputra river basin. These two distinctive groups reveal a significant spatial autocorrelation, indicating that lakes of each group are likely affected by the same factors. Both low-high and high-low groups are scattered without strong spatial clustering, and only account for $18 \%$ of all lakes. This suggests that lakes of these groups are likely affected by different dominant factors (e.g., increasing/decreasing precipitation, evaporation, and glacier melt recharge) or strong anisotropy of climate forcing factors (e.g., precipitation and evaporation) as they respond differently compared to neighboring lakes. Interestingly, these clusters seem to be direction-dependent, that is, the autocorrelation is stronger in the east-west direction compared to the north-south direction. This may imply a spatial coherence of precipitation and evaporation in the east-west direction, which is in line with the previous findings (Chen et al., 2016; Z. Wang et al., 2017).

\subsection{Interannual Variations of Lake Levels}

Figure 6 clearly reveals that lake levels show a general rising trend during the past decade, but the rising rates are variable in time. Generally, three phases can be seen regardless of lake area. Specifically, a fast increase in lake level occurred during 2010-2013, followed by a steady or slight drop during 2013-2016, and then another fast increase since 2017. All six groups show a similar variation. There is no obvious 

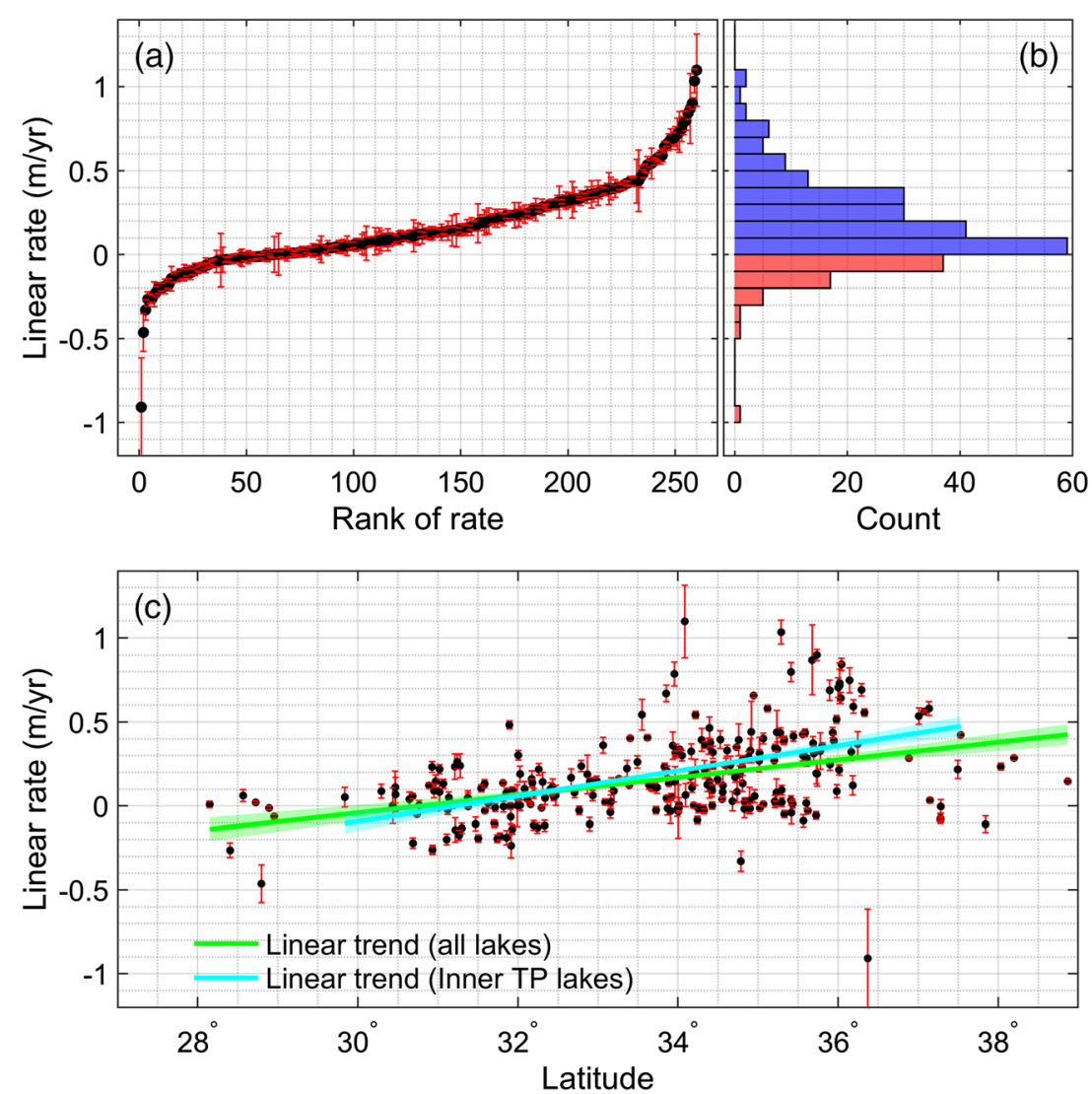

Figure 3. Statistics of lake level changing rates (robust linear regression). (a) Ranked rates (black dots) with standard deviations (red bars); (b) histogram of rates (24\% negatives in red vs. $76 \%$ positives in blue); (c) rates distribution along latitude (shaded areas indicate $95 \%$ confidence intervals).

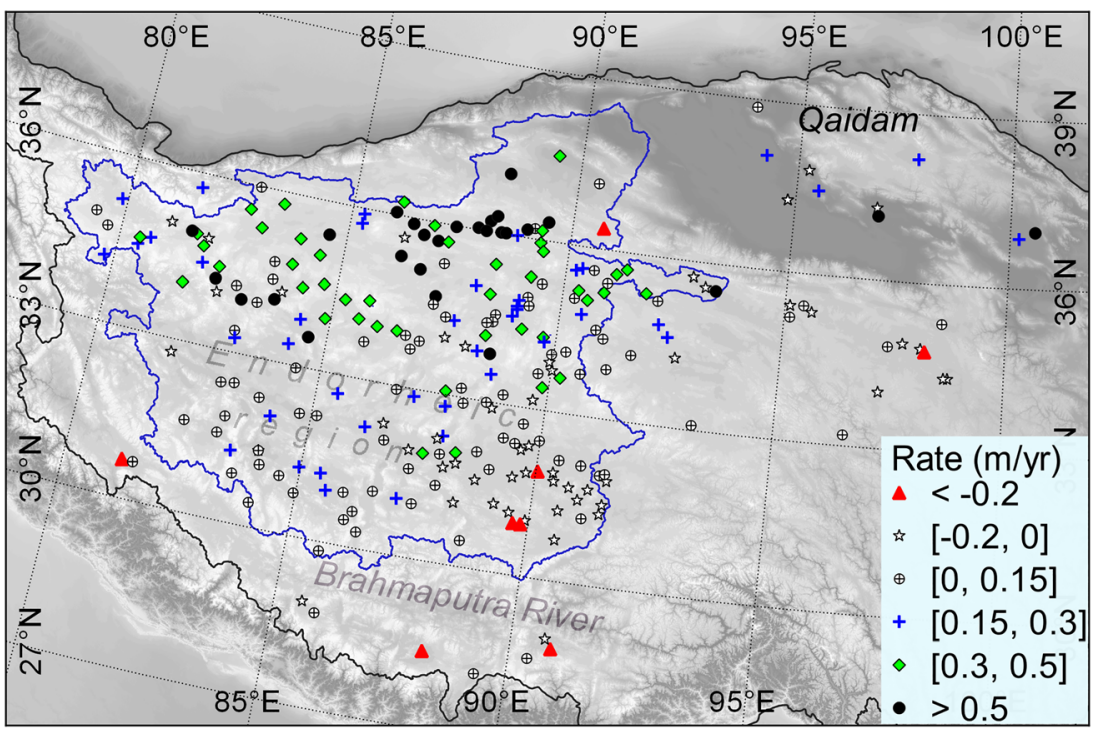

Figure 4. The spatial variation of lake level change rates. Endorheic region, that is, the Inner Tibetan Plateau, is highlighted in blue. 


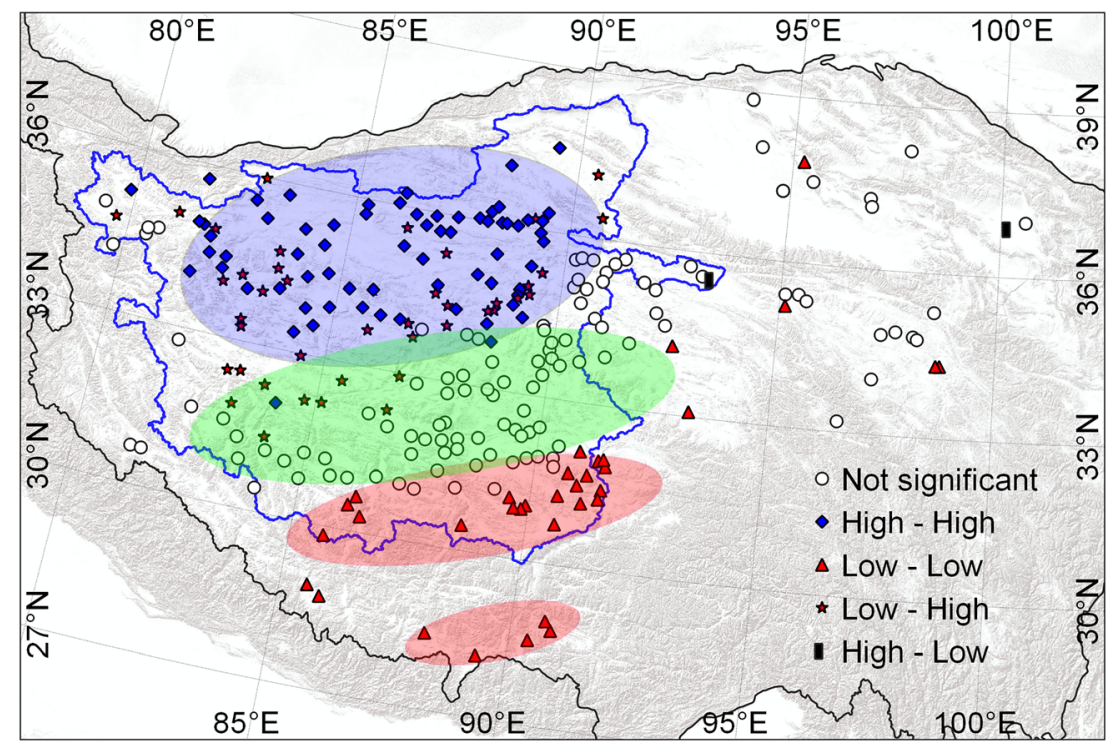

Figure 5. The spatial distribution of cluster types based on local Moran's $I$.
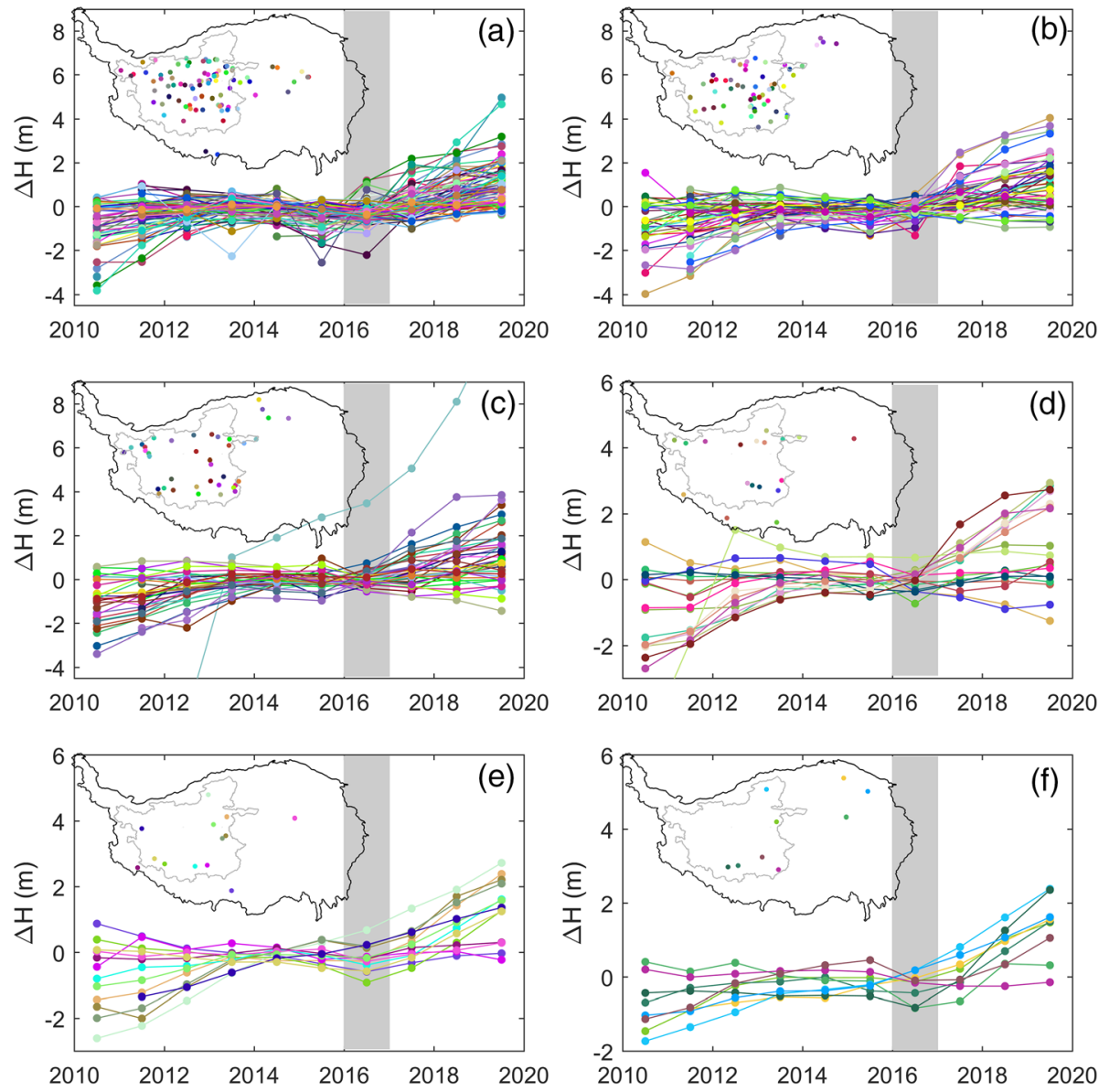

Figure 6. Anomaly of annual mean lake level for six groups based on lake area, that is, (a) $10-50 \mathrm{~km}^{2}$, (b) $50-100 \mathrm{~km}^{2}$, (c) $100-200 \mathrm{~km}^{2}$, (d) $200-400 \mathrm{~km}^{2}$, (e) $400-600 \mathrm{~km}^{2}$, (f) $>600 \mathrm{~km}^{2}$, respectively. Accompanying inset maps show the location of corresponding lakes. Note that 220 lakes are used based on the length of annual lake level time series $(\geq 9)$. 

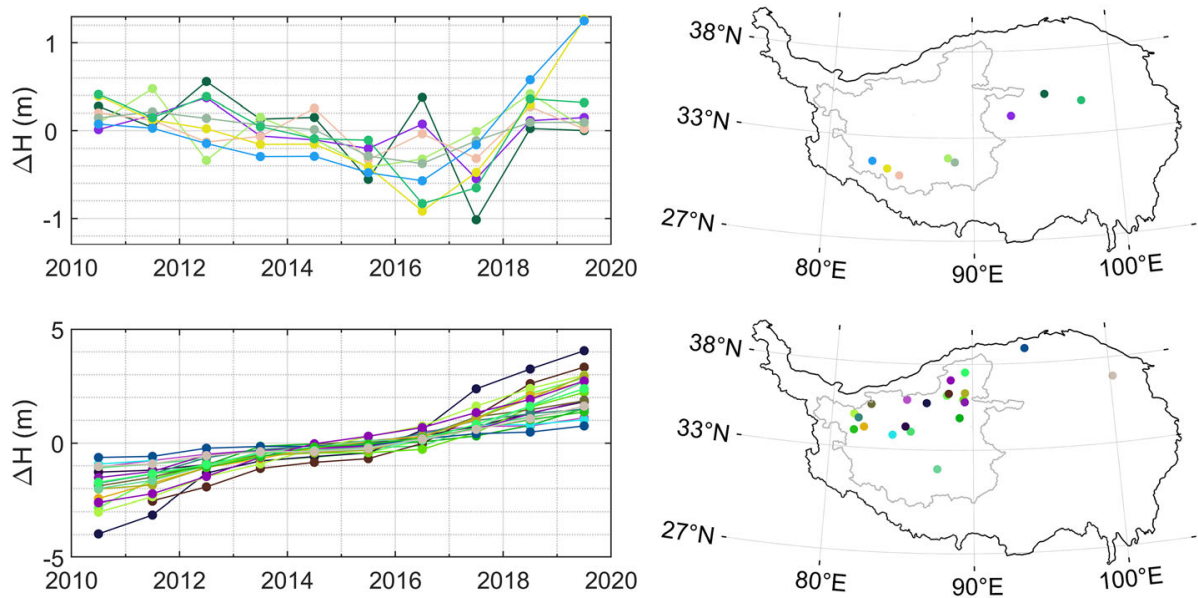

Figure 7. (Top) anomaly of annual mean lake level presenting V-shape and lake location map. (Bottom) anomaly of annual mean lake level showing monotonous rising and lake location map.

difference between large and small lakes (Figure 6). Statistically, 89\% of all lakes have a negative anomaly in 2015/2016, and 52\% have negative anomalies in both 2015 and 2016. Referred to lake level in 2013, 70\% have a negative increase in 2015/2016. In other words, $70 \%$ of all lakes experienced a drop in lake level in 2015/2016. Based on these findings, it is clear that climate variability plays an important role controlling the interannual variations of lake levels.

Nevertheless, there are other distinct patterns, that is, declining followed by rising lake level and monotonous rising lake level (Figure 7). All but one lake with monotonous rising pattern are located beyond $33^{\circ} \mathrm{N}$. Lakes with a V-shape pattern do not show clear clustering. Interestingly, none of those are located in the northern part of the Inner TP. Note that these two patterns are present in both small and large lakes. There is no obvious relationship between pattern and lake area. However, these two groups only account for $13 \%$ of all lakes.

Mean decadal change of lake level is $2.19 \mathrm{~m}$ (median $1.85 \mathrm{~m}$ ), of which $56 \%(1.22 \mathrm{~m})$ occurs in the last 3 years after the decline $(-0.3 \mathrm{~m})$ in 2016. This can be clearly seen from Figure 6. A maximum change of $26 \mathrm{~m}$ is found at Salt Lake (Figure 6c), followed by changes of 5 to $10 \mathrm{~m}$ in 19 lakes. These lakes are generally continuously increasing in lake level, similar to those shown in Figure 7.

\subsection{Lake Storage and Terrestrial Water Storage Changes}

Figure 8 depicts the volumetric lake storage changes. The map is characterized by the overwhelming dominance of increasing rates (green dots). Spatially, most of those with a net gain are located in the northeastern part of the Inner TP. The sum of positive change rates is $7.85 \mathrm{~km}^{3} / \mathrm{yr}$, while negative changes sum to $-0.63 \mathrm{~km}^{3} / \mathrm{yr}$. A similar rate was reported for the period of 2002-2015 (F. Yao et al., 2018). There are 21 lakes gaining water at a rate larger than $0.1 \mathrm{~km}^{3} / \mathrm{yr}$ due to either larger areas (in the south) or higher increases in water level (in the north). These lakes contribute with $65 \%\left(5.08 \mathrm{~km}^{3}\right)$ of the total storage gain although only accounting for $11 \%(21 / 200)$ of all lakes. In particular, the Qinghai Lake has the maximum gaining rate of $1.24 \mathrm{~km}^{3} / \mathrm{yr}$, followed by Ayakkum Lake $\left(0.38 \mathrm{~km}^{3} / \mathrm{yr}\right)$, Selin Co $\left(0.33 \mathrm{~km}^{3} / \mathrm{yr}\right)$, Salt Lake $\left(0.32 \mathrm{~km}^{3} / \mathrm{yr}\right)$, and Aqqikkol Lake $\left(0.3 \mathrm{~km}^{3} / \mathrm{yr}\right)$ (see Figure 8).

TWS from GRACE/GRACE-FO shows similar patterns to that of lake storage change (Figure 8), which implies that lake storage change dominates the TWS change. In general, contrasting trends appear over the north and south TP. Positive trends are present in north TP with a strong center in the northeastern Inner TP. This is in good agreement with lake storage change shown in Figure 8. On the contrary, the exorheic region, that is, the Brahmaputra River basin, shows a negative trend of $-1.12 \mathrm{~cm} / \mathrm{yr}$. Nevertheless, it should be kept in mind that because of the limited spatial resolution of GRACE, reliable results of mass changes can only be resolved in regions larger than $10,000 \mathrm{~km}^{2}$. Therefore, we cannot interpret Figure 8 on a lake-by-lake basis. For example, even the Qinghai Lake has a quite large storage gain, but no exceptional TWS increase shows nearby. 


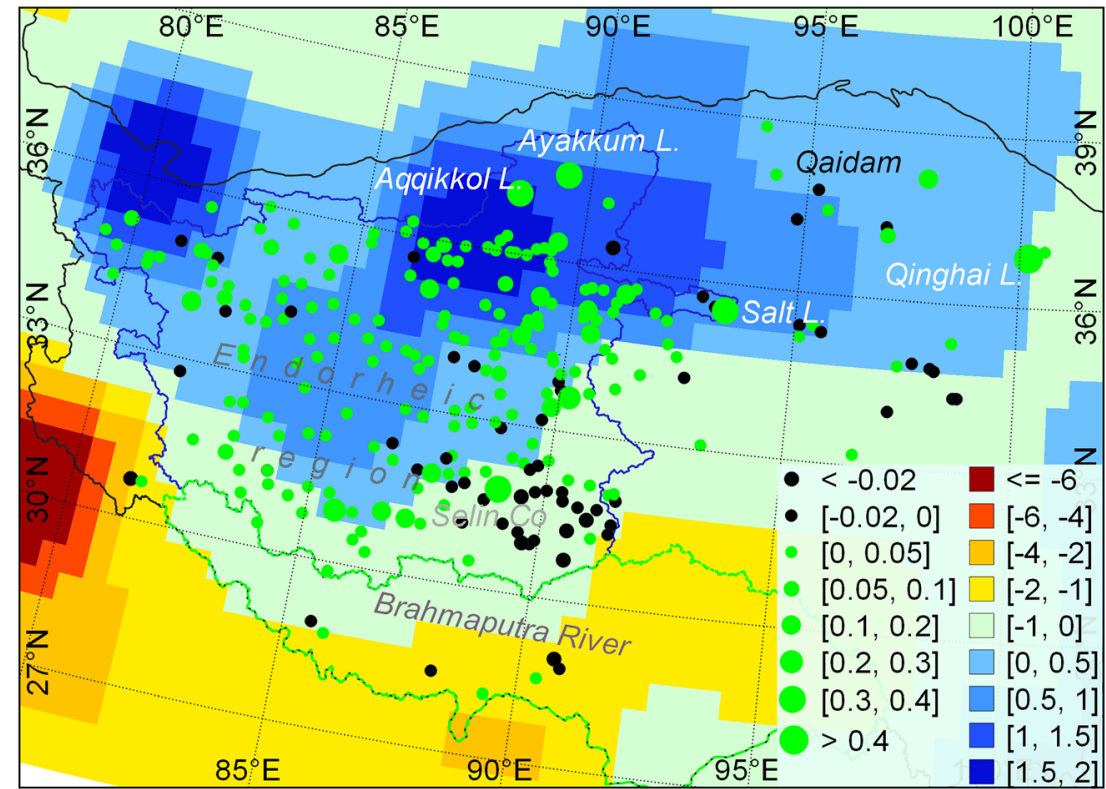

Figure 8. Trend of water storage during 2010-2019. Background colored grid indicates trend of terrestrial water storage $(\mathrm{cm} / \mathrm{yr})$ derived from GRACE/GRACE-FO. Front dot indicates trend of lake storage in units $\mathrm{of}_{\mathrm{km}}^{3} / \mathrm{yr}$. Top five lakes with largest net gains are labeled.

The net gain of lake water storage in the Inner TP is ca. $63.3 \mathrm{~km}^{3}$ over the past decade, while TWS shows a similar gain of $70.5 \mathrm{~km}^{3}$. Clearly, the positive rate of lake storage change is not constant (Figure 9). In the first 3 years, the annual lake storage was increasing, and then it slowed down with a hiatus of 3 years. However, TWS had a distinct decline during 2013-2016. In the last 3 years, both lake storage and TWS had a sharp increase, that is, $60 \%$ and $119 \%$ increases referred to that of 2016, respectively. Note that TWS in 2017 might be underestimated while overestimated in 2018 due to data gaps in the second half of 2017 and the first half of 2018. However, these gaps will not affect decadal cumulated TWS. Figure 9 also shows that lake storage change dominates the TWS change in wet years (e.g., 2011, 2012, and 2017-2019), while lake storage mitigates TWS decline in dry years (2013-2016). Therefore, lake storage has a big influence on TWS variation on interannual scale by acting as a buffer against climate extremes. On a decadal timescale, TWS change is dominated by lake

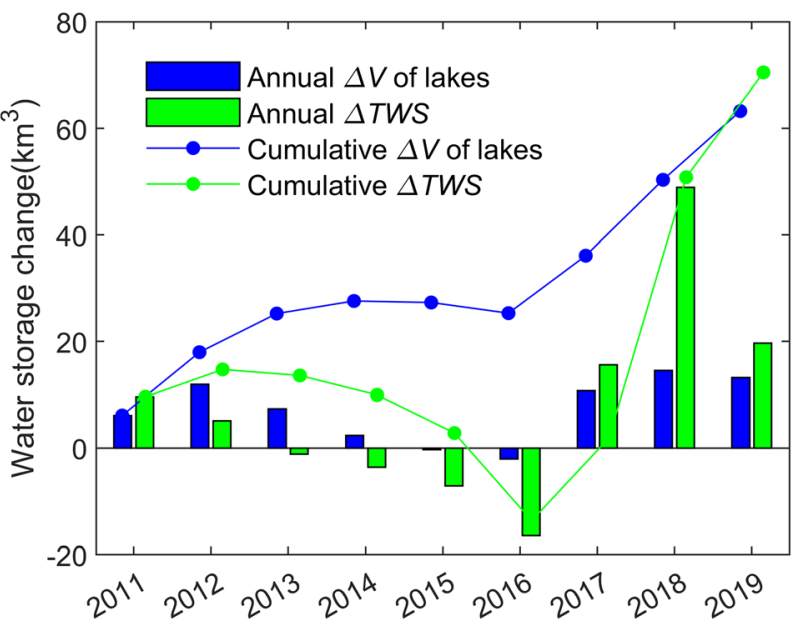

Figure 9. Changes of lake storage and terrestrial water storage over the Inner TP. Bar indicates annual storage change relative to previous year, while dotted line indicates cumulative annual storage change. Note that area of lakes in the Inner TP account for $88 \%$ of that of all lakes over the TP. water storage change.

\section{Discussion}

It is well acknowledged that the westerlies and the Indian summer monsoon play major roles in transporting water vapor to the TP (Curio et al., 2015; Pan et al., 2019; Z. Wang et al., 2017; T. Yao et al., 2015; Ye, 1981), and lake level rise in the north TP is largely attributed to increased precipitation (Song et al., 2014; F. Yao et al., 2018; Zhang, Yao, et al., 2017). The increased atmospheric moisture has been extensively discussed. Yao, Thompson, et al. (2012) found that the precipitation increase (1970-2010) in the eastern Pamir is linked to the strengthening westerlies. Zhang, Tang, and Chen (2017) attributed the precipitation increase (1979-2013) over the Inner TP to enhanced water vapor transport from the Indian Ocean during summer and local moisture recycling. $\mathrm{Li}, \mathrm{Su}$, et al. (2019) showed that the increased atmospheric transport of water from the Indian Ocean, rather than from local recycling, is mostly the cause of the increased precipitation over the Inner TP during 1979-2015. A recent study attributed the increase of summer 
Table 2

Lake Level Change and Storage Changes of the Inner TP Over Different Periods

\begin{tabular}{lcccc}
\hline & $2010-2014$ & $2015-2016$ & $2017-2019$ & $2010-2019$ \\
\hline Mean lake level change $(\mathrm{m})$ & 1.01 & -0.35 & 1.35 & 2.32 \\
TWS change $\left(\mathrm{km}^{3}\right)$ & 9.9 & -23.6 & 84.1 & 70.5 \\
Lake storage change $\left(\mathrm{km}^{3}\right)$ & 27.6 & -2.3 & 37.9 & 63.3 \\
\hline
\end{tabular}

precipitation to weakened westerlies (Sun et al., 2020). However, the debate is still going on. One major challenge is data uncertainty, which obscures the interplay of atmospheric water transport and precipitation over the huge area of TP (Curio et al., 2015) as well as the mechanisms and causality for the interactions between large-scale circulations and the heating effect of the TP (Z. Wang et al., 2017).

Table 2 shows lake level change, lake storage change, and TWS change over different periods. Considering that the studied lakes cover nearly all lakes larger than $20 \mathrm{~km}^{2}$ (202 according to F. Yao et al., 2018), the uncertainty is within 5\% (Yang et al., 2017; F. Yao et al., 2018). Overall, the net gain rate of 2010-2019 is similar to that of 2000-2011 and of 2002-2015 according to Song et al. (2013) and F. Yao et al. (2018). This indicates that the overall increasing trend did not slow down at decadal scale. One clear finding is that the 2015/16 El Niño had a strong influence on the Tibetan lakes (Table 2) via reduced precipitation (Figures 6 and 10). This also resulted in soil moisture drought and TWS deficit (Figure 10). This is in line with the assumption that precipitation was the major contributor to lake variation

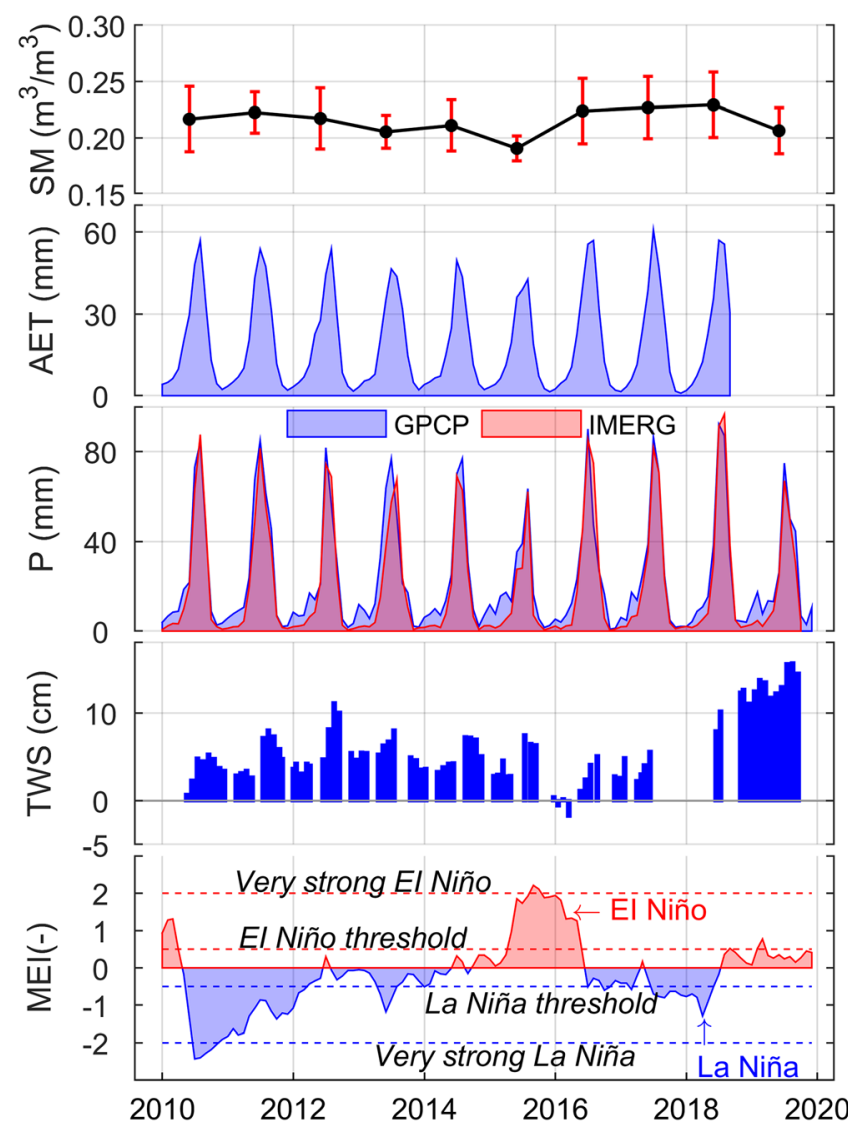

Figure 10. (Top) average soil moisture of surface soil layer (2 to $5 \mathrm{~cm}$ ) during summer monsoon months (June, July, August, and September) over the Inner TP; red bars indicate standard deviations. (Second) monthly actual evapotranspiration over the Inner TP. (Third) monthly GPCP and IMERG precipitation over the Inner TP. (Fourth) Monthly TWS (some observations are not available). (Bottom) multivariate ENSO index (MEI).
(F. Yao et al., 2018; G. Zhang et al., 2020). However, we are unsure which sources of precipitation (local recycling vs. external transport) that had been reduced. Clearly, the above normal precipitation in 2010-2012 led to the increase in lake levels (Figure 6) and a marked increase of TWS in 2012, which may relate to the very strong 2010/11 La Niña event. Moreover, the weak 2016/17 and 2017/18 La Niña led to persistent above normal precipitation during 2016-2018, which explains the sharp rise of lake levels in recent 3 years as shown in Table 2 and Figures 6 and 9 . Interestingly, precipitation, soil moisture, and evapotranspiration are very well correlated with El Niño and La Niña events, but TWS shows a delayed response to El Niño and La Niña as well as precipitation. This indicates that water storage changes in Inner TP are likely to be more resistant to meteorological droughts. However, the strength of El Niño and La Niña is not directly proportional to the precipitation effects, such as those in 2011, 2013, and 2018 (Figure 10), probably due to their different characteristics (Yeo \& Kim, 2014). It should be noted that the two precipitation products have small discrepancies, especially in cold season. GPM IMERG is about 3\% lower compared to GPCP. Nevertheless, they are in agreement regarding long-term trends on interannual timescale.

Continuous lake level rise leads to increasing water resources, which favors ecosystem resilience and biomass production. On the other hand, lake level rise also has negative effects. Many lakes have been connected permanently or intermittently due to their continuous rising, such as Migriggyangzham Co and Dorsoidong Co (Jiang et al., 2017b). Moreover, lake level rise poses threats to transport infrastructure, such as the S301, S205 provincial roads, and so forth, which cross many lakeshores (e.g., Selin Co and Tangra Yumco). One of the extreme scenarios is lake outburst, which can be illustrated using a specific case, that is, Zhuonai Lake (Figure 11). The outburst of Zhuonai Lake in 2011 has resulted in a chain reaction of environmental impacts (Hwang et al., 2016; Yao, Liu, et al., 2012). The outflow recharges Kusai Lake, which further releases water and recharges Salt Lake downstream. The continuous lake level rise of Salt Lake ( $>25 \mathrm{~m}$ since 2011) poses a huge threat to the 


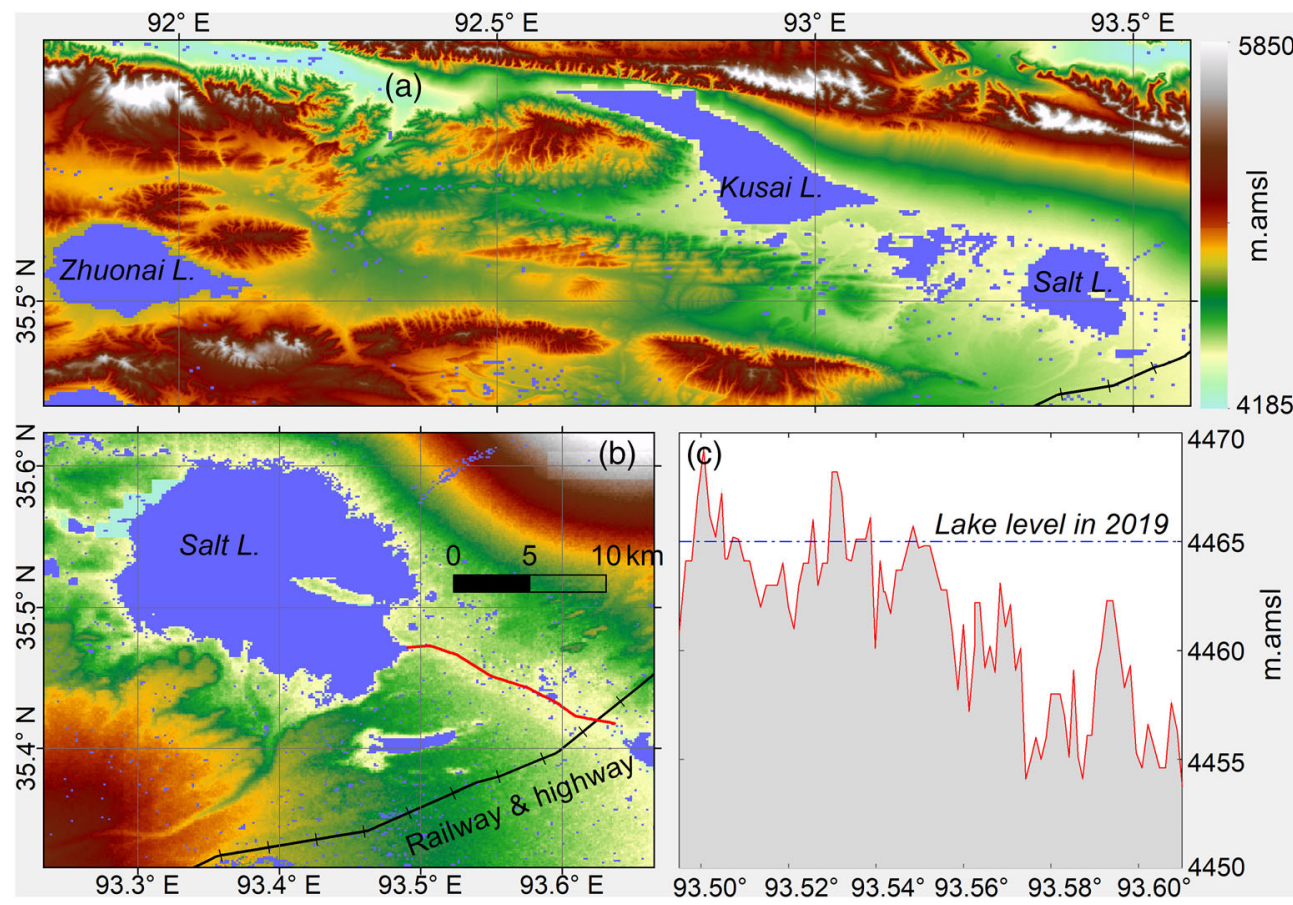

Figure 11. Illustration of outburst risk at Salt Lake. (a) Locations of Zhuonai Lake, Kusai Lake, Salt Lake, and the Qinghai-Tibet railway and highway. (b) Zoom-in of Salt Lake, railway \& highway, and a potential channel.

(c) Longitudinal elevation profile of the line shown in (b).

Qinghai-Tibet railway and highway $12 \mathrm{~km}$ running along the southern corner of Salt Lake (Figure 11). As shown in Figure 11c, present lake level is approaching the highest boundary. The railway and highway are under a big threat of inundation if the level of the three lakes continues to rise. The projected precipitation is likely increasing in the future (Duan et al., 2019); therefore, some measures should be considered, for example, dam, water transfer, and so forth, to alleviate the outburst risk. In addition, rising lake levels also threaten local villages and pastoral communities due to the inundation of vast areas of grazing land as well as cultural and religious influences (Mao et al., 2018; Nyima \& Hopping, 2019).

One should be aware that the CryoSat-2 is unable to track the seasonal variability over most lakes due to the low temporal resolution, that is, 369-day full repeat and 30-day subcycle repeat. Only dozens of very large lakes have quasi-monthly time series. It is possible to obtain 10-day or 27-day lake level time series using short-repeat altimeters, such as Jason-1/2/3 and Sentinel-3A/B, but only for a limited number of lakes due to the lower spatial coverage. This does not allow us to study the larger picture of seasonal variations. Indeed, the pattern of seasonal variations of lake levels can vary between lakes depending mostly on the runoff generation mechanisms. It is a very important question and requires further investigation. Future studies on this issue could be carried out based on hypsometry, which can be established using altimetry (e.g., CryoSat-2, SARAL-DF, and Sentinel-3A/B) and imagery (Landsat, GF, Sentinel-1A/B, and Sentinel-2A/B).

\section{Summary and Conclusions}

We clearly demonstrate the value of CryoSat-2 for monitoring inland lakes due to its superior data coverage. Measurements from CryoSat-2 during the past decade, have covered over 500 Tibetan lakes $\left(>10 \mathrm{~km}^{2}\right)$, which is far beyond the coverage of missions with a short-repeat cycle, such as Jason series and Envisat/ Sentinel series. Although the closed-loop mode occasionally results in invalid measurements, time series for 262 lakes have been retrieved in this study. This presents a bigger picture of how the Tibetan lakes changed in the past decade under a warming climate.

Lake level time series show a positive trend for $76 \%$ (58\% significantly) of the lakes and a negative trend for $24 \%$ (13\% significantly). Lakes located in the north TP generally have higher rates, while those in the south 
show smaller or negative rates. All lakes with a marked positive trend $(>0.5 \mathrm{~m} / \mathrm{yr})$ are located beyond $33^{\circ} \mathrm{N}$, mainly in the Inner TP. On interannual timescale, three stages are found, that is, quick rising during 2010-2013, followed by a steady or slight decline during 2013-2016, and then another fast rising since 2017. The highest increase in lake level is seen over the last 3 years, contributing $56 \%$ of decadal increase on average.

Lake storage change is dominated by the increase in lake level. The sum of positive change rates is $7.85 \mathrm{~km}^{3} / \mathrm{yr}$ while $-0.63 \mathrm{~km}^{3} / \mathrm{yr}$ for negative ones. Particularly, the Inner TP lakes have gained a water volume of $63.3 \mathrm{~km}^{3}$, constituting $90 \%$ of the total water storage gain $\left(70.5 \mathrm{~km}^{3}\right)$ during the past decade. The latest 3 years have seen a sharp increase of both lake storage and TWS, that is, $60 \%$ and $119 \%$ increases relative to 2016 , respectively.

The whole picture of lake changes clearly shows the quick response of the Tibetan Plateau to climate change. Lake level rise indeed has positive effects, such as increasing water availability, sustaining lake ecosystem, and so forth, but it can also pose threats to pastoral livelihoods, traditional culture of local community, infrastructure, and so forth (Nyima \& Hopping, 2019). In this regard, satellite altimetry is of great value for monitoring lake level dynamics. A continuous monitoring of lake dynamics is vital to our understanding of and community-based adaptation to the regional changes responding to climate change. Along with CryoSat-2, the upcoming Surface Water and Ocean Topography Mission (SWOT) and SMall Altimetry Satellites for Hydrology (SMASH) (Verron et al., 2020) will greatly facilitate monitoring network.

\section{Data Availability Statement}

CryoSat-2 data can be accessed online (https://gpod.eo.esa.int/). Note that an account of GPOD https://gpod. eo.esa.int/ is required. GRACE/-FO data are downloaded from JPL (https://podaac.jpl.nasa.gov/GRACE). Soil moisture can be downloaded online (https://catalogue.ceda.ac.uk/uuid/2d4a50f390064820a9dcc2fcf7ac4b18). Evapotranspiration data are available online (https://www.gleam.eu/\#downloads). Climate data are available online (https://psl.noaa.gov/gcos_wgsp/Timeseries/ and https://gpm.nasa.gov/data-access/ data-sources).

\section{Acknowledgments}

This study is funded by the Danida Fellowship Centre through the EOForChina project (File number: 18-M01-DTU) and the Innovation Fund Denmark (File number: 8087-00002B). The ESA GPOD/SARvatore service, ESA Climate Change Initiative, NASA JPL, NCAR, GPM, and GLEAM teams are gratefully acknowledged for making the data sets publicly available.

\section{References}

Adler, R., Sapiano, M., Huffman, G., Wang, J.-J., Gu, G., Bolvin, D., et al. (2018). The global precipitation climatology project (GPCP) monthly analysis (new version 2.3) and a review of 2017 global precipitation. Atmosphere, 9(4), 138. https://doi.org/10.3390/ atmos 9040138

Anselin, L. (1995). Local indicators of spatial association-LISA. Geographical Analysis, 27(2), 93-115. https://doi.org/10.1111/j.15384632.1995.tb00338.x

Bercher, N., Dinardo, S., Lucas, B. M., Fleury, S., Calmant, S., Crétaux, J.-F., et al. (2013). Applications of CryoSat-2 SAR \& SARIn modes for the monitoring of river water levels. Proceedings of cryosat third user workshop, 12-14 March 2013, 1-7. Retrieved from http://chronos. altihydrolab.fr/2013-03-12DresdenCryosatThirdUserWorkshop/Bercher.2013a\%28DresdenPaper\%29CryoSat-2SARSARinhydro.pdf

Chen, D., Tian, Y., Yao, T., \& Ou, T. (2016). Satellite measurements reveal strong anisotropy in spatial coherence of climate variations over the Tibet Plateau. Scientific Reports, 6(1), 1-9. https://doi.org/10.1038/srep30304

Chen, D., Xu, B., Yao, T., Guo, Z., Cui, P., Chen, F., et al. (2015). Assessment of past, present and future environmental changes on the Tibetan Plateau. Kexue Tongbao/Chinese Science Bulletin, 60(32), 3025-3035. https://doi.org/10.1360/N972014-01370

Crétaux, J.-F., Abarca-del-Río, R., Bergé-Nguyen, M., Arsen, A., Drolon, V., Clos, G., \& Maisongrande, P. (2016). Lake volume monitoring from space. Surveys in Geophysics, 37(2), 269-305. https://doi.org/10.1007/s10712-016-9362-6

Crétaux, J. F., \& Birkett, C. (2006). Lake studies from satellite radar altimetry. Comptes Rendus Geoscience, 338(14-15), 1098-1112. https:// doi.org/10.1016/j.crte.2006.08.002

Curio, J., Maussion, F., \& Scherer, D. (2015). A 12-year high-resolution climatology of atmospheric water transport over the Tibetan Plateau. Earth System Dynamics, 6(1), 109-124. https://doi.org/10.5194/esd-6-109-2015

Dinardo, S., Fenoglio-Marc, L., Buchhaupt, C., Becker, M., Scharroo, R., Joana Fernandes, M., \& Benveniste, J. (2018). Coastal SAR and PLRM altimetry in German Bight and West Baltic Sea. Advances in Space Research, 62(6), 1371-1404. https://doi.org/10.1016/j. asr.2017.12.018

Dinardo, S., Lucas, B., \& Benveniste, J. (2014). SAR altimetry processing on demand service for CryoSat-2 at ESA G-POD. In Proceeding of the 2014 conference on Big Data from Space (BiDS'14) (pp. 299-302). https://doi.org/10.2788/1823

Duan, W., Hanasaki, N., Shiogama, H., Chen, Y., Zou, S., Nover, D., et al. (2019). Evaluation and future projection of Chinese precipitation extremes using large ensemble high-resolution climate simulations. Journal of Climate, 32(8), 2169-2183. https://doi.org/10.1175/JCLID-18-0465.1

Durack, P. J., Wijffels, S. E., \& Matear, R. J. (2012). Ocean salinities reveal strong global water cycle intensification during 1950 to 2000. Science, 336(6080), 455-458. https://doi.org/10.1126/science.1212222

Fetterer, F. M., Drinkwater, M. R., Jezek, K. C., Laxon, S. W. C., Onstott, R. G., \& Ulander, L. M. H. (1992). Sea ice altimetry. In F. D. Carsey (Ed.), Microwave remote sensing of sea ice, Geophysical Monograph Series (Vol. 68, pp. 111-135). Washington, D. C.: American Geophysical Union. https://doi.org/10.1029/GM068p0111 
Garcia, E. S., Sandwell, D. T., \& Smith, W. H. F. (2014). Retracking Cryosat-2, Envisat and Jason-1 radar altimetry waveforms for improved gravity field recovery. Geophysical Journal International, 196(3), 1402-1422. https://doi.org/10.1093/gji/ggt469

Holland, P. W., \& Welsch, R. E. (1977). Robust regression using iteratively reweighted least-squares. Communications in Statistics - Theory and Methods, 6(9), 813-827. https://doi.org/10.1080/03610927708827533

Huffman, G. J., Bolvin, D. T., \& Nelkin, E. J. (2017). Integrated multisatellite retrievals for GPM (IMERG) technical documentation.

Hwang, C., Cheng, Y.-S., Han, J., Kao, R., Huang, C.-Y., Wei, S.-H., \& Wang, H. (2016). Multi-decadal monitoring of lake level changes in the Qinghai-Tibet Plateau by the TOPEX/Poseidon-family altimeters: Climate implication. Remote Sensing, 8(6), 446. https://doi.org/ $10.3390 / \mathrm{rs} 8060446$

Immerzeel, W. W., Van Beek, L. P. H., \& Bierkens, M. F. P. (2010). Climate change will affect the Asian water towers. Science, 328(5984), 1382-1385. https://doi.org/10.1126/science.1183188

Jiang, L., Andersen, O. B., Nielsen, K., Zhang, G., \& Bauer-Gottwein, P. (2019). Influence of local geoid variation on water surface elevation estimates derived from multi-mission altimetry for Lake Namco. Remote Sensing of Environment, 221(November 2018), 65-79. https:// doi.org/10.1016/j.rse.2018.11.004

Jiang, L., Madsen, H., \& Bauer-Gottwein, P. (2019). Simultaneous calibration of multiple hydrodynamic model parameters using satellite altimetry observations of water surface elevation in the Songhua River. Remote Sensing of Environment, 225, 229-247. https://doi.org/ 10.1016/j.rse.2019.03.014

Jiang, L., Nielsen, K., Andersen, O. B., \& Bauer-Gottwein, P. (2017a). CryoSat-2 radar altimetry for monitoring freshwater resources of China. Remote Sensing of Environment, 200, 125-139. https://doi.org/10.1016/j.rse.2017.08.015

Jiang, L., Nielsen, K., Andersen, O. B., \& Bauer-Gottwein, P. (2017b). Monitoring recent lake level variations on the Tibetan Plateau using CryoSat-2 SARIn mode data. Journal of Hydrology, 544, 109-124. https://doi.org/10.1016/j.jhydrol.2016.11.024

Jiang, L., Nielsen, K., Dinardo, S., Andersen, O. B., \& Bauer-Gottwein, P. (2020). Evaluation of Sentinel-3 SRAL SAR altimetry over Chinese rivers. Remote Sensing of Environment, 237(October 2019), 111546. https://doi.org/10.1016/j.rse.2019.111546

Jiang, L., Schneider, R., Andersen, O. B., \& Bauer-Gottwein, P. (2017). CryoSat-2 altimetry applications over rivers and lakes. Water, 9(3), 211. https://doi.org/10.3390/w9030211

Keith Raney, R. (1998). The delay/doppler radar altimeter. IEEE Transactions on Geoscience and Remote Sensing, 36(5 PART 1), $1578-1588$. https://doi.org/10.1109/36.718861

Kleinherenbrink, M., Lindenbergh, R. C., \& Ditmar, P. G. (2015). Monitoring of lake level changes on the Tibetan Plateau and Tian Shan by retracking Cryosat SARIn waveforms. Journal of Hydrology, 521, 119-131. https://doi.org/10.1016/j.jhydrol.2014.11.063

Koblinsky, C. J., Clarke, R. T., Brenner, A. C., \& Frey, H. (1993). Measurement of river level variations with satellite altimetry. Water Resources Research, 29(6), 1839-1848. https://doi.org/10.1029/93WR00542

Lazhu, Y. K., Wang, J., Lei, Y., Chen, Y., Zhu, L., Ding, B., \& Qin, J. (2016). Quantifying evaporation and its decadal change for Lake Nam Co, central Tibetan Plateau. Journal of Geophysical Research: Atmospheres, 121, 7578-7591. https://doi.org/10.1002/ 2015JD024523

Lei, Y., Zhu, Y., Wang, B., Yao, T., Yang, K., Zhang, X., et al. (2019). Extreme Lake level changes on the Tibetan Plateau associated with the 2015/2016 El Niño. Geophysical Research Letters, 46, 5889-5898. https://doi.org/10.1029/2019GL081946

Li, X., Long, D., Huang, Q., Han, P., Zhao, F., \& Wada, Y. (2019). High-temporal-resolution water level and storage change data sets for lakes on the Tibetan Plateau during 2000-2017 using multiple altimetric missions and Landsat-derived lake shoreline positions. Earth System Science Data, 11(4), 1603-1627. https://doi.org/10.5194/essd-11-1603-2019

Li, Y., Su, F., Chen, D., \& Tang, Q. (2019). Atmospheric water transport to the Endorheic Tibetan Plateau and its effect on the hydrological status in the region. Journal of Geophysical Research: Atmospheres, 124, 12,864-12,881. https://doi.org/10.1029/ 2019JD031297

Liu, Y., Chen, H., Wang, H., \& Qiu, Y. (2018). The impact of the NAO on the delayed break-up date of lake ice over the southern Tibetan Plateau. Journal of Climate, 31(22), 9073-9086. https://doi.org/10.1175/JCLI-D-18-0197.1

Mao, D., Wang, Z., Yang, H., Li, H., Thompson, J. R., Li, L., et al. (2018). Impacts of climate change on Tibetan lakes: Patterns and processes. Remote Sensing, 10(3), 358. https://doi.org/10.3390/rs10030358

Martens, B., Miralles, D. G., Lievens, H., van der Schalie, R., de Jeu, R. A. M., Fernández-Prieto, D., et al. (2017). GLEAM v3: Satellite-based land evaporation and root-zone soil moisture. Geoscientific Model Development, 10(5), 1903-1925. https://doi.org/10.5194/ gmd-10-1903-2017

Moran, P. A. (1950). Notes on continuous stochastic phenomena. Biometrika, 37(1-2), 17-23. https://doi.org/10.1093/biomet/37.1-2.17

Nielsen, K., Stenseng, L., Andersen, O. B., Villadsen, H., \& Knudsen, P. (2015). Validation of CryoSat-2 SAR mode based lake levels. Remote Sensing of Environment, 171, 162-170. https://doi.org/10.1016/j.rse.2015.10.023

Notaro, M., Holman, K., Zarrin, A., Fluck, E., Vavrus, S., \& Bennington, V. (2013). Influence of the Laurentian great lakes on regional climate. Journal of Climate, 26(3), 789-804. https://doi.org/10.1175/JCLI-D-12-00140.1

Nyima, Y., \& Hopping, K. A. (2019). Tibetan Lake expansion from a pastoral perspective: Local observations and coping strategies for a changing environment. Society and Natural Resources, 32(9), 965-982. https://doi.org/10.1080/08941920.2019.1590667

Pan, C., Zhu, B., Gao, J., Kang, H., \& Zhu, T. (2019). Quantitative identification of moisture sources over the Tibetan Plateau and the relationship between thermal forcing and moisture transport. Climate Dynamics, 52(1-2), 181-196. https://doi.org/10.1007/ s00382-018-4130-6

Pekel, J.-F., Cottam, A., Gorelick, N., \& Belward, A. S. (2016). High-resolution mapping of global surface water and its long-term changes. Nature, 1-19. https://doi.org/10.1038/nature20584

Qiao, B., Zhu, L., \& Yang, R. (2019). Temporal-spatial differences in lake water storage changes and their links to climate change throughout the Tibetan Plateau. Remote Sensing of Environment, 222, 232-243. https://doi.org/10.1016/j.rse.2018.12.037

Rodríguez, E., Morris, C. S., \& Belz, J. E. (2006). A global assessment of the SRTM performance. Photogrammetric Engineering \& Remote Sensing, 72(3), 249-260. https://doi.org/10.14358/PERS.72.3.249

Schneider, R., Godiksen, P. N., Villadsen, H., Madsen, H., \& Bauer-Gottwein, P. (2017). Application of CryoSat-2 altimetry data for river analysis and modelling. Hydrology and Earth System Sciences, 21(2), 751-764. https://doi.org/10.5194/hess-21-751-2017

Schneider, R., Ridler, M. E., Godiksen, P. N., Madsen, H., \& Bauer-Gottwein, P. (2018). A data assimilation system combining CryoSat-2 data and hydrodynamic river models. Journal of Hydrology, 557, 197-210. https://doi.org/10.1016/j.jhydrol.2017.11.052

Scott, R. W., \& Huff, F. A. (1996). Impacts of the Great Lakes on regional climate conditions. Journal of Great Lakes Research, 22(4), 845-863. https://doi.org/10.1016/S0380-1330(96)71006-7

Sheng, Y., \& Yao, T. (2009). Editorial: Integrated assessments of environmental change on the Tibetan plateau. Environmental Research Letters, 4(4). https://doi.org/10.1088/1748-9326/4/4/045201 
Song, C., Huang, B., \& Ke, L. (2013). Modeling and analysis of lake water storage changes on the Tibetan Plateau using multi-mission satellite data. Remote Sensing of Environment, 135, 25-35. https://doi.org/10.1016/j.rse.2013.03.013

Song, C., Huang, B., Ke, L., \& Richards, K. S. (2014). Seasonal and abrupt changes in the water level of closed lakes on the Tibetan Plateau and implications for climate impacts. Journal of Hydrology, 514, 131-144. https://doi.org/10.1016/j.jhydrol.2014.04.018

Sun, J., Yang, K., Guo, W., Wang, Y., He, J., \& Lu, H. (2020). Why has the inner Tibetan Plateau become wetter since the mid-1990s? Journal of Climate, 33(19), 8507-8522. https://doi.org/10.1175/jcli-d-19-0471.1

Tapley, B. D., Watkins, M. M., Flechtner, F., Reigber, C., Bettadpur, S., Rodell, M., et al. (2019). Contributions of GRACE to understanding climate change. Nature Climate Change, 5(5), 358-369. https://doi.org/10.1038/s41558-019-0456-2

Verron, J., Bonnefond, P., Andersen, O., Ardhuin, F., Bergé-Nguyen, M., Bhowmick, S., et al. (2020). The SARAL/AltiKa mission: A step forward to the future of altimetry. Advances in Space Research, 1-21. https://doi.org/10.1016/j.asr.2020.01.030

Wang, J., Song, C., Reager, J. T., Yao, F., Famiglietti, J. S., Sheng, Y., et al. (2018). Recent global decline in endorheic basin water storages. Nature Geoscience, 11(12), 926-932. https://doi.org/10.1038/s41561-018-0265-7

Wang, Z., Duan, A., Yang, S., \& Ullah, K. (2017). Atmospheric moisture budget and its regulation on the variability of summer precipitation over the Tibetan plateau. Journal of Geophysical Research: Atmospheres, 122, 614-630. https://doi.org/10.1002/2016JD025515

Watkins, M. M., Wiese, D. N., Yuan, D.-N., Boening, C., \& Landerer, F. W. (2015). Improved methods for observing Earth's time variable mass distribution with GRACE using spherical cap mascons. Journal of Geophysical Research: Solid Earth, 120, 2648-2671. https://doi. org/10.1002/2014JB011547

Wingham, D. J., Francis, C. R., Baker, S., Bouzinac, C., Brockley, D., Cullen, R., et al. (2006). CryoSat: A mission to determine the fluctuations in Earth's land and marine ice fields. Advances in Space Research, 37(4), 841-871. https://doi.org/10.1016/j.asr.2005.07.027

Wu, Y., Huang, A., Yang, B., Dong, G., Wen, L., Zhang, Z., et al. (2019). Numerical study on the climatic effect of the lake clusters over Tibetan Plateau in summer. Climate Dynamics, 53(9-10), 5215-5236. https://doi.org/10.1007/s00382-019-04856-4

Yang, K., Yao, F., Wang, J., Luo, J., Shen, Z., Wang, C., \& Song, C. (2017). Recent dynamics of alpine lakes on the endorheic Changtang Plateau from multi-mission satellite data. Journal of Hydrology, 552, 633-645. https://doi.org/10.1016/j.jhydrol.2017.07.024

Yao, F., Wang, J., Yang, K., Wang, C., Walter, B. A., \& Crétaux, J. F. (2018). Lake storage variation on the endorheic Tibetan Plateau and its attribution to climate change since the new millennium. Environmental Research Letters, 13(6). https://doi.org/10.1088/1748-9326/aab5d3

Yao, T., Thompson, L., Yang, W., Yu, W., Gao, Y., Guo, X., et al. (2012). Different glacier status with atmospheric circulations in Tibetan Plateau and surroundings. Nature Climate Change, 2(9), 663-667. https://doi.org/10.1038/nclimate1580

Yao, T., Wu, F., Ding, L., Sun, J., Zhu, L., Piao, S., et al. (2015). Multispherical interactions and their effects on the Tibetan Plateau's earth system: A review of the recent researches. National Science Review, 2(4), 468-488. https://doi.org/10.1093/nsr/nwv070

Yao, T., Xue, Y., Chen, D., Chen, F., Thompson, L., Cui, P., et al. (2018). Recent third pole's rapid warming accompanies cryospheric melt and water cycle intensification and interactions between monsoon and environment: Multidisciplinary approach with observations, modeling, and analysis. Bulletin of the American Meteorological Society, 100(3), 423-444. https://doi.org/10.1175/bams-d-17-0057.1

Yao, X., Liu, S., Sun, M., Guo, W., \& Zhang, X. (2012). Changes of Kusai Lake in Hoh Xil region and causes of its water overflowing. Acta Geographica Sinica, 67(5).

Ye, D. (1981). Some characteristics of the summer circulation over the Qinghai-Xizang (Tibet) plateau and its neighborhood. Bulletin of the American Meteorological Society, 62(1), 14-19. https://doi.org/10.1175/1520-0477(1981)062<0014:SCOTSC >2.0.CO;2

Yeo, S.-R., \& Kim, K.-Y. (2014). Global warming, low-frequency variability, and biennial oscillation: An attempt to understand the physical mechanisms driving major ENSO events. Climate Dynamics, 43(3-4), 771-786. https://doi.org/10.1007/s00382-013-1862-1

Zhang, C., Tang, Q., \& Chen, D. (2017). Recent changes in the moisture source of precipitation over the Tibetan Plateau. Journal of Climate, 30(5), 1807-1819. https://doi.org/10.1175/JCLI-D-15-0842.1

Zhang, G., Luo, W., Chen, W., \& Zheng, G. (2019). A robust but variable lake expansion on the Tibetan Plateau. Science Bulletin, 64(18), 1306-1309. https://doi.org/10.1016/j.scib.2019.07.018

Zhang, G., Yao, T., Piao, S., Bolch, T., Xie, H., Chen, D., et al. (2016). Climate change drives extensive and drastically different alpine lake changes on Asia's high plateaus during the past four decades. Geophysical Research Letters, 44, 252-260. https://doi.org/10.1002/ 2016GL072033

Zhang, G., Yao, T., Shum, C. K., Yi, S., Yang, K., Xie, H., et al. (2017). Lake volume and groundwater storage variations in Tibetan Plateau's endorheic basin. Geophysical Research Letters, 44, 5550-5560. https://doi.org/10.1002/2017GL073773

Zhang, G., Yao, T., Xie, H., Kang, S., \& Lei, Y. (2013). Increased mass over the Tibetan Plateau: From lakes or glaciers? Geophysical Research Letters, 40, 2125-2130. https://doi.org/10.1002/grl.50462

Zhang, G., Yao, T., Xie, H., Yang, K., Zhu, L., Shum, C. K., et al. (2020). Response of Tibetan Plateau lakes to climate change: Trends, patterns, and mechanisms. Earth-Science Reviews, 208, 103269. https://doi.org/10.1016/j.earscirev.2020.103269 